\title{
CAN ORGANIZATIONAL CULTURE BE DESIGNED?
}

\author{
Olga Tararukhina \\ Ph.D., Adjunct Faculty, The Chicago School of Professional Psychology (USA)
}

\begin{abstract}
This paper explores a theoretical approach to intentionally designing a culture that is unique to the company and needed for a new organization to succeed. This approach includes outlining cultural elements beyond a values statement, the support and process of living into them so that company culture could be aligned to its strategy. It also makes an argument for and articulates the process of a specific sequence of determining purpose, mission, vision, strategy, and culture that makes for an aligned organization. The practical approach to designing organizational culture includes steps and stages of cultural development from the early stages when the founding leaders are incepting the new business, to building the first team, to growth and sustaining culture. This paper then articulates the role of the leader and practical actions that leaders can and should be taking on a regular basis to sustain or shift the culture of their organization to be supporting the strategy. It further demonstrates how interpersonal relationships at all levels further stabilize the young culture and what needs to be done to ensure it sustains and doesn't get eroded when an organization rapidly grows in the number of employees.
\end{abstract}

Keywords: Organizational culture, design, strategy, alignment.

\section{Introduction}

It has been established and broadly understood that organizational culture is a powerful force in achieving organizational success, delivering results against strategy, as well as creating a community (Schaine, 2004, 2015; Cooke, 2015; Katzenbach, 2012). While it is rather well understood in the literature how organizational culture gets formed and sets in, an approach to intentionally forming organizational culture from the beginning of the new organization, does not seem to be well developed. In practice, many entrepreneurs focus primarily on establishing the process of the business to deliver results: best business models, standard processes and products, digital processes, talented and dedicated team, as well as ensuring financial stability of the new enterprise. They can often leave culture outside of their focus, and culture forms on its own, as an afterthought or an accident. It has become clear that creating value statements does not create culture: those typically remain "the words on the wall". That afterthought or accident can potentially do more harm than good if the culture does not support business strategy (Tararukhina, 2019, b). Therefore, there is an advantage to be gained for newer companies and startups if their founders intentionally design the culture from the beginning and practice it so that it could take hold and sustain itself.

This paper presents an original approach to intentionally designing organizational culture: starting with the prerequisites to determining what the culture is going to create, articulating the role of the leader and interpersonal relationships.

This approach is developed based on our theoretical and empirical research, as well as practitioner consultant work.

\section{State of the art}

Most theoretical and practical views on organizational culture approach it either as a stand alone phenomenon, or as a phenomenon based on the definitions of culture that we demonstrated earlier were incomplete (Tararukhina, 2019, b), such as employee value proposition, or reputation. These elements are part of the organization but they are not its culture. 
Most cultural theories and research are done in mature organizations, and there is little empirical evidence about designing organizational culture intentionally from the first day of business life. Given that, we don't always know if leaders made mistakes and whether they were aware of them, which makes startups different from mature organizations from the standpoint of organizational culture.

Following E. Shein's definition of culture: how work gets done around here (Schein, 2004; Schein, 2015), any work on organizational culture should also follow the organization's strategy and be done within its context. Strategy depends on company's vision, purpose, and identity. In other words, we propose that there are several prerequisites of identifying the culture that a newly established organization needs, and we suggest that they should be identified in a specific sequence, described in the next paragraph.

New businesses and companies are typically organized either from scratch by new entrepreneurs (whether they have business education and management experience or not), or they are spun off by existing companies as a subsidiary or a new business, or by a serial entrepreneur who has experience in striating up companies. In the former situation, new entrepreneurs are often focused on the financial and marketing aspect of their new organization. This is a understandable approach, however if the culture that is being designed, does not help the business, they might not see that they need to pivot and where; designing culture intentionally from the beginning may seem like a daunting task, however it will be easier in the long run: there will be less need to change and shift culture when the organization may be vulnerable. We argue that the inception of the company is an important moment to be intentional about creating company's culture.

The latter two scenarios are more likely to look at intentionally building a new culture. The organization's strategy and mission may be different from the parent company. Serial entrepreneurs may have noticed what was effective and what was not, in their previous endeavors. If they haven't, the risks are higher to create the same culture expecting different results from the new business. For example, if the parent company is a hierarchical bank with a long history of celebrating individual achievement while its new business is about developing new investment products which would require the new business to be creative and innovative, it may be difficult to make that a reality under hierarchy and individualism when the new organization needs, for example, team work and interdependence with autonomy given to those teams to explore, experiment, and test products before offering them to the client.

Founding leaders (founders who also lead the company) get to make those decisions, which make their role crucial in defining, designing, maintaining, and shifting organizational culture. Lastly, interpersonal relationships play a key role in maintaining the organizational culture, making it real, as we have demonstrated before (Tararukhina, 2019, a); here we will elaborate on what sustains the young culture in the short and longer run, when the organization grows and new employees may be coming in numbers outnumbering the original group.

\section{New perspectives / contributions}

Some of the key differences between a mature organization and a startup from the perspective of organizational culture remain in the experience that a mature company has in the market and in the industry; it may also be quite established and difficult to pivot, while a startup can be nimble and flexible. As we have previously demonstrated (Tararukhina, 2019, b) the relationship between strategy and culture can be strong or weak, as well as culture itself can be intense or loose; in a startup however these relationships barely exist, there may be a potential for it. Culture develops naturally through a shared social experience, which can be overlooked by the founding leaders. That is why intentional design of the organizational culture can give an organization an edge in its business and mission.

\subsection{Prerequisites to organizational culture}

We already mentioned that what comes before culture is strategy. But what comes before strategy? And how can one create a culture aligned to the strategy? Before the newly formed entity or a business that is only being conceived, could effectively determine what culture it needs and how to go about establishing it, it needs to identify the following elements if its unique identity:

1. Purpose is the answer to the question: Why does this company we exist? This answer articulates organization's specific impact on the lives of its customers, which would be missing if the organization didn't exist.

2. Mission is a declaration of organization's general intention to accomplish something. It provides a direction to the company both in the present and projecting into the future.

3. Vision describes the organization as it would appear in a future successful state, as a result of the pursuit of its mission, having achieved or accomplished all its strategic goals.

4. Strategy explains how the organization will move forward, how it will advance its interests. The structure of strategy contains 3 elements: a diagnosis, a guiding policy, and coherent action. He guiding policy specifies the approach to dealing with the obstacles called out in the diagnosis. 
Coherent actions are feasible coordinated policies, resource commitments, and actions designed to carry out the guiding policy (Rumelt, 2011). Strategy explains how the company will become its vision and achieve its mission.

5. Culture is a shared way of how the work gets done around here to deliver on the strategy.

This list is organized in this specific sequence because each following element builds on the previous one: one cannot determine how the organization will move forward (strategy) if it is not clear where it is going (mission and vision). In this perspective, these elements must be aligned for an organization to be clear how to it will be successful and what may be in the way of its success. We suggest that this is the sequence to determine the organization's identity. The next paragraph outlines an approach and a process of designing an organizational culture for a new organization. This process is agnostic of the founding leaders' prior experience or new organization's ownership status.

\subsection{Original approach to designing organizational culture}

After clarifying and aligning all prerequisites to defining culture, the question becomes what is the process of designing culture. As articulated by E. Schein (Schein, 2004), culture establishes based on a natural repeated social experiences that a group shares together, which then are interpreted into creating rules and norms that subsequently are attached a meaning, becoming the actual, real values that the organization lives by (not the declared ones). Eventually they become undiscussable, undoubted beliefs of what is true in this given organization. This is how culture happens when it is not intentionally designed: a lot of variables are left to happen as they will include sometimes not the best influence from the company founders (e.g. inconsistency, or consistency/prevalence of the opposite of what the strategy/mission needs). Figure 1 demonstrates our model of organizational culture as articulated earlier (Tararukhina, 2019, a) with five layers that go from more visible and experiential to those that are invisible and typically not talked about.

Figure 1. "Onion" model of the five layers of organizational culture.

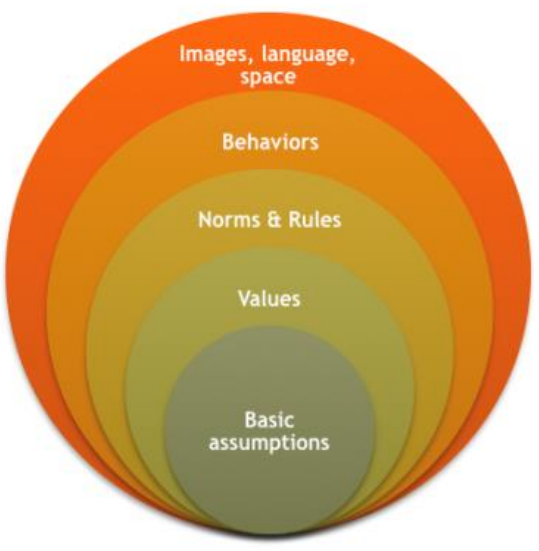

"In this model, the layers represent:

- Images / language / space: observable, tangible materials and objects;

- Behaviors: observable actions people take in interactions and in doing their work;

- Norms: shared understanding of the distinction between what's right and wrong, what's acceptable and what's not; Rules: dos and don'ts as well as knowing or the ability to forecast their consequences;

- Values: what is held important when members of the organization take action;

- Basic assumptions: beliefs that we assume to be true and do not question or typically even discuss." (Tararukhina, 2019, b)

An intentional approach that we are proposing here, starts from determining the norms as the core of organizational culture (layer 3, in the middle of the model in Fig. 1). It would require leaders to adhere to these norms and influence the rest of the organization to practice them. Behaviors as well as values will ensue from well articulated norms. Behaviors will align with the norms to demonstrate living into these norms, and values will be created by attaching meaning to the norms when articulating why these norms are important in this organization, demonstrating what is the impact of practicing them, and how the organization as a whole and its individual members benefit. That articulation can happen through the organizational dialogue in formal and informal settings, such as town halls, team stand up meetings, and everything in between, including dedicated sessions. 
As we postulated before, culture that helps organization's success, meets several criteria at the same time: it needs to be aligned with purpose, vision, mission and strategy that it need to help execute, and foster belonging, make it clear how to belong here (Tararukhina, 2019, b). They need to be the context in which the norms are being defined by the founding leaders and their first teams. These norms should answer two questions:

- What will help us achieve our mission?

- What will hinder us achieving our mission?

And the answers to the first question should be retained as norms. Initially determined norms may eventually evolve and multiply as organization grows in complexity, but the beginning needs not to be complex.

\subsection{Role of a founder/senior leader in designing organizational culture}

Founding leaders' role is significant in establishing and developing organizational culture (Schein, 2004). Their role extends from modeling the norms, as well as behaviors and articulating values, to helping others practice them. Helping others practice the norms can happen in both formal and informal settings by influencing, such as reinforcing, encouraging, supporting examples of effectively living into the norms, redirecting where needed by asking leading questions or by reconnecting back to the norms and values. Culture develops as a social process, social learning, and its development even intentional should apply the same rules.

When the organizational culture is intentionally designed from the inception of the organization (e.g. when founders define their norms before they even enter a partnership agreement), their professional relationships get moulded by the norms they want their organization to have. Those norms may simple or complex, but leaders need to take them seriously and demonstrate their commitment to other members of the organization.

Therefore, it is instrumental that senior leaders adhere to the organizational norms in their relationships with their direct reports: modeling, supporting, reinforcing, reconnecting as needed. This should be happening in all forums: formal, informal, team and organizational meetings as well as one on one meetings.

\subsection{Role of interpersonal relationships in designing organizational culture}

Interpersonal relationships between leaders are not the only interpersonal relationships that the organizational culture is based. Culture evolves through socialization and social learning. Consequently, culture lives in interpersonal relationships as much as in group meetings, it gets transmitted and transformed through the vehicle of interpersonal workplace relationships: they are an important carrier of organizational culture (Tararukhina, 2019, a).

The new organization's culture needs to be strong not to get eroded, which means that it needs to have norms that are strongly held by organizational members, values that support its strategy and mission. When newcomers will be coming to the organization, especially if they outnumber the incumbents, incumbents need to be able to effectively enculturate newcomers to avoid culture erosion: teach them the way things are done around here and help them practice the norms first, just the founding leaders did at the very beginning. This applies to both intentionally designed and naturally occurring cultures: they can get eroded by newcomers who don't know it. What is potentially dangerous about culture erosion is that culture would become looser and therefore less effective at supporting the strategy and achievement of the mission, which may make the company vulnerable.

\section{Practical implications}

We believe that this approach can be helpful to entrepreneurs and leaders of mature companies who set up affiliates. This approach is aimed to make it simple enough to follow, and be able to reduce the abstraction and nebulousness that accompany the concept of organizational culture. It is quite possible to determine those norms in a short period of time and simple to practice, which should increase the likelihood of that practice. Making it fun and simple may also be helpful to help culture stick, as well as to help entrepreneurs who have so many things to take care of when staring up a company, focus on what's most important. Described approach provides simple and actionable steps that help organizational leaders take ownership of their companies' culture and create it intentionally. This would help organizational clarity and ease of getting alignment, reduce time lost on misunderstandings and misalignment, focus on fulfilling the organization's purpose. 


\section{Originality and value}

This approach and theory puts responsibility and ownership of culture of their organization on the leaders, where it belongs and not on any consultant or a designated person in the organization. It attempts to bring simplicity and clarity to the concept of culture and practice of working with it. It provides a framework of culture design that is respects each company's uniqueness, agnostic of industries, and provides a roadmap of progressively shifting the culture in an evolutionary way.

\section{Questions for future research}

For the future empirical and theoretical research, it appears interesting to investigate how much time and effort this intentional approach saves founders and leaders on starting the new organization intentionally, making it happen has opposed to letting it happen naturally.

\section{References}

Cooke R. (2015, October). How Culture Really Works. Paper presented at the 1st Ultimate culture conference. Chicago, IL.

Edmondson A.C. (2019). The fearless organization. John Wiley \& Sons.

Katzenbach J. (2012). Culture change that sticks. Harvard Business Review. July-August 2012. Retrieved from https://hbr.org/2012/07/cultural-change-that-sticks

Kluckhohn F.L., Strodtbeck F.R. (1961). Variations in value orientations. Row, Peterson and Company.

Lewin K. (1997). Resolving social conflicts. Field theory in social science. (Reprinted ed.) American Psychological Association.

Quinn R.E. (1996). Deep change: Discovering the leader within. John Wiley \& Sons.

Rumelt R.P. (2011). Good strategy / bad strategy. The difference and why it matters. NY, NY: Crown Business.

Schein E. (2004), Organizational culture and leadership. (3rd ed.) San Francisco, CA: John Wiley $\&$ Sons.

Schein E. (2015, October). When and How to Think about Culture. Paper presented at the 1st Ultimate culture conference. Chicago, IL.

Tararukhina O. (2016). Cross-cultural variations in satisfaction with interpersonal relationships in the workplace. Doctoral dissertation, Saint Petersburg State University, Saint Petersburg, Russia. Retrieved from http://www.dslib.net/soc-psixologia/kross-kulturnye-osobenno sti-udovletvorjonnosti-mezhlichnostnymi-otnoshenijami-v.html

Tararukhina O. (2019, April) c. Workplace Relationships as Symptoms of the US Business Culture. Paper presented at the annual meeting of Midwestern Psychological Association. Chicago, IL.

Tararukhina O. (2019, March) a. Specifics of Workplace Relationships in Russia. Paper presented at the third biennial International Convention of Psychological Science (ICPS). Paris, France.

Tararukhina O. (2019, March) b. American Business Culture through the Lens of Workplace Relationships. Paper presented at the third biennial International Convention of Psychological Science (ICPS). Paris, France.

Tararukhina O. (2019, May) a. Workplace Relationships as a Symptom of Organizational Culture and a Lever for Culture Transformation. Paper presented at the InPACT 2019 conference. Zagreb, Croatia.

Tararukhina O. (2019, May). b. Effective Measure of Organizational Culture. Paper presented at the InPACT 2019 conference. Zagreb, Croatia.

Tararukhina O.V., Gurieva S.D. (2015). Social'no-psihologicheskaya model' razvitija mezhlichnostnyh otnoshenij v organizacii [Social-psychological model of development of interpersonal relationships in the workplace]. // Sovremennye issledovaniya social'nyh problem. 2015, 1 (21), 26-40. 